\title{
EL DISEÑO DE LOS DIARIOS ESPAÑOLES EN EL CREPÚSCULO DE LA PRENSA
}

\section{THE DESIGN OF THE SPANISH NEWSPAPERS IN THE TWILIGHT OF THE PRESS}

https://doi.org/10.33732/ixc/10/03Eldise

\section{José Ignacio Armentia Vizuete Universidad del País vasco ignacio.armentia@ehu.eus orcid.org/0000-0002-5786-3670}

Flora Marín Murillo Universidad del País Vasco flora.marin@ehu.eus orcid.org/0000-0003-2823-598X

Los autores pertenecen al Grupo de Investigación MediaIker de la UPV/EHU (GIU19/024) 
Resumen: En este artículo se analiza el diseño de la prensa española durante la última década. Las modificaciones que se han realizado en la morfología de los diarios no han sido tan espectaculares como las que ocurrieron en los años anteriores y posteriores a la llegada del nuevo siglo. La crisis a la que se enfrentan los periódicos impresos, con una imparable caída de ventas en los últimos lustros y con un descenso de la inversión publicitaria en dicho sector, ha podido influir en una mayor moderación a la hora de afrontar transformaciones de gran calado. De hecho, en la mayoría de las cabeceras son aún reconocibles las aportaciones formales de principio de siglo. La omnipresencia del color, el uso de tipografías diferenciadas y la apuesta por los formatos de doble velocidad de lectura son algunas de las características que permanecen en unas publicaciones que, en general, han reducido sus dimensiones.

Palabras clave: diarios; diseño; prensa española; maquetación.

Abstract: This article analyzes the design of the Spanish press during the last decade. The changes that have been made in the morphology of the newspapers have not been as spectacular as those that occurred in the years before and after the arrival of the new century. The crisis facing the press, with an unstoppable drop in sales for a long time and with a decrease in advertising investment in these media, has probably influenced greater restraint when undertaking deeper transformations. In fact, in most newspapers the contributions that were incorporated into their designs at the beginning of the century are still recognizable. The omnipresence of color, the use of different typefaces and the commitment to double reading speed formats are some of the characteristics that remain in publications that, in general, have reduced their dimensions.

Keywords: Newspapers; Design; Spanish press; Layout. 


\section{Introducción}

La última década del siglo XX y los primeros años del siglo XXI podrían ser considerados como la época dorada del diseño periodístico en España. No sería aventurado afirmar que en ese momento se pusieron las bases del moderno diseño periodístico español. Como recogía Díaz Nosty $(1992,55)$, tan sólo en el periodo 1990-92 medio centenar de diarios regionales y locales afrontaron procesos de rediseño. Según dicha fuente, un número análogo de cabeceras renovaron en dicha época sus rotativas para incorporar equipos adaptados al offset-color.

La mayor parte de estos rediseños planteaban alternativas visuales al modelo formal establecido por El País en 1976 (maqueta modular, uniformidad tipográfica basada en la Times, empleo de la cursiva para los títulos de opinión, etc.), obra de Reinhard Gäde, con la colaboración de Julio Alonso. Puede decirse que 1989, con el nacimiento de El Mundo, diseñado por Carmelo G. Caderot, y con la nueva imagen de La Vanguardia (Milton Glaser), marcó el punto de partida a estas nuevas tendencias. Cabría referirse también a la aparición de El Sol en 1990, diseñado por Roger Black, Eduardo Danilo y Ricardo Curtis. A pesar de su efímera vida (desapareció en 1992) este diario fue uno de los pioneros en una serie de propuestas visuales (renovación tipográfica, empleo del color, apuesta por la infografía, arrevistamiento...) que posteriormente serían adoptadas por la mayor parte de las cabeceras nacionales. Como señalaba el propio Curtis, el fracaso empresarial de $\mathrm{El} \mathrm{Sol} \mathrm{«no} \mathrm{ensombrece} \mathrm{para} \mathrm{nada} \mathrm{la} \mathrm{corriente} \mathrm{de} \mathrm{aire} \mathrm{fresco} \mathrm{que} \mathrm{trajo} \mathrm{al}$ diseño de la prensa española (2007: 77)».

Entre las remodelaciones formales que se produjeron en la última década del siglo pasado podrían citarse la de La Voz de Galicia (1992, Xosé Luís Vilela), Avui (1994, Roger Black), Información (1998, Antoni Cases), El Correo de Andalucía (2000, Antoni Cases), Abc (1999, W. Bernard y Milton Glaser (1999), Diario 16 (1999, Roger Vallés), El Correo (2000, A. Torregrosa y A. Palmer) o El Periódico de Catalunya (2000, Cases i Asociats), por referirnos únicamente a algunas de ellas.

Entre las características de estas remodelaciones figuran las siguientes:

-Generalización del empleo del color. El País y El Mundo, por ejemplo, lo incorporaron en 1998.

-Variedad tipográfica. No es habitual el uso de la misma fuente en todos los elementos del diario. Además, frente a la omnipresencia de tipos como la Times y Helvética en años precedentes, los diarios optan por el empleo de otras familias, como las Swift, la Nimrod o la Madison, entre 
las romanas, y la Fraklin Gothik, la Bureau Grotesque o la Frutiger, entre las de palo seco.

- Se generaliza la pauta de 5 columnas. No hay que olvidar que todavía en los años noventa diarios como Heraldo de Aragón se componían a 6 columnas.

- Se opta por un estilo más arrevistado, con un menor énfasis vertical.

- Las mejoras en la impresión y el uso del color permiten una mejor incorporación de la imagen a las páginas de los diarios.

-Se generalizan los formatos de lectura rápida: textos más breves, más despieces, sumarios, etc.

-Refuerzo de los suplementos temáticos semanales.

En la apuesta de la prensa española por mejorar su diseño hay que tener en cuenta, al menos, tres factores. Por un lado, los avances tecnológicos derivados de la aplicación de sistemas de autoedición descentralizados y con software en continua evolución y mejora a los procesos de redacción, montaje y preimpresión facilitaron enormemente las labores de producción de los diarios; a lo que hay que añadir las novedades incorporadas en el terreno de offset-color y en la transmisión de los datos para la preparación de las planchas desde las redacciones a los centros de impresión.

En segundo lugar (ver tabla 1), la inversión publicitaria global en los diarios se mantiene por encima de los 1.000 millones de euros tanto en los últimos años de siglo XX como durante la primera década del siglo XXI. De hecho, según Infoadex, hasta 2011 los diarios constituyeron el segundo soporte mediático con mayor atracción publicitaria, detrás de la televisión.

Por otro lado (ver tabla 2), la difusión de la prensa en España mantuvo una tendencia creciente, en términos globales, hasta 2004, si bien cabeceras como El Mundo o La Vanguardia consiguieron prolongar el crecimiento hasta 2007.

Tabla 1. Inversión publicitaria en medios convencionales (millones de $\mathbf{C}$ )

\begin{tabular}{|l|r|r|r|r|r|r|}
\hline & \multicolumn{1}{|c|}{$\mathbf{2 0 1 9}$} & \multicolumn{1}{c|}{$\mathbf{2 0 1 5}$} & \multicolumn{1}{c|}{$\mathbf{2 0 1 0}$} & \multicolumn{1}{c|}{$\mathbf{2 0 0 5}$} & \multicolumn{1}{c|}{$\mathbf{2 0 0 0}$} & \multicolumn{1}{c|}{1995} \\
\hline Diarios & 485,2 & 658,9 & 1124,4 & 1666,4 & 1689,30 & 1118,4 \\
\hline TV & 2002,8 & 2011,3 & 2479,5 & 2950,8 & 2270,75 & 1321,2 \\
\hline Internet & 2296,2 & 1249,8 & 789,5 & 120,5 & 53,36 & \\
\hline Radio & 486,4 & 454,4 & 548,5 & 609,9 & 500,95 & 346,5 \\
\hline Otros & 681,2 & 642,3 & 907,6 & 1297,2 & 1132,23 & 757,1 \\
\hline Total & 5951,8 & 5016,7 & 5849,5 & 6644,8 & 5646,59 & 3543,2 \\
\hline
\end{tabular}

Fuente: Infoadex. Elaboración propia. 
Tabla 2. Los 10 diarios de información general más vendidos en España

\begin{tabular}{|l|r|r|r|r|r|}
\hline & \multicolumn{1}{|c|}{2019} & \multicolumn{1}{c|}{$\mathbf{2 0 1 5}$} & \multicolumn{1}{c|}{$\mathbf{2 0 1 0}$} & \multicolumn{1}{c|}{2005} & \multicolumn{1}{c|}{2000} \\
\hline El País & 110.386 & 221.390 & 370.080 & 453.602 & 436.302 \\
\hline La Vanguardia & 88.254 & 129.073 & 200.370 & 208.139 & 191.673 \\
\hline El Mundo & 80.719 & 126.369 & 284.901 & 314.591 & 292.063 \\
\hline Abc & 68.128 & 107.801 & 259.539 & 278.166 & 291.950 \\
\hline La Voz de Galicia & 57.539 & 72.377 & 97.016 & 103.399 & 107.850 \\
\hline El Periódico & 54.009 & 87.706 & 124.648 & 170.181 & 184.251 \\
\hline El Correo & 53.640 & 72.856 & 102.378 & 124.843 & 132.113 \\
\hline La Razón & 51.585 & 80.108 & 118.466 & 140.088 & 68.122 \\
\hline El Diario Vasco & 41.063 & 53.593 & 71.948 & 89.259 & 94.499 \\
\hline La Nueva España & 32.218 & 43.838 & 56.796 & 59.710 & 57.560 \\
\hline Difusión total & 1.526 .763 & 2.104 .441 & 3.626 .897 & 4.196 .412 & 4.260 .689 \\
\hline
\end{tabular}

Fuente: OJD, AEDE y Noticias de la Comunicación. Elaboración propia.

Con el nuevo siglo se materializan una serie de cambios que no sólo influirán en un mayor inmovilismo en el aspecto de los diarios, sino que incluso llegarán a arrojar dudas sobre la propia supervivencia del papel como soporte fundamental de la prensa.

Entre los avances tecnológicos de los años 90 no se puede soslayar la popularización de Internet y, especialmente, el desarrollo de la web, cuyo nacimiento se atribuye a los trabajos de Tim Berners-Lee y Robert Cailliau en 1990. En España, el desembarco de la prensa diaria en la web se produce a partir de 1995, año en el que cabeceras como Abc, Avui, La Vanguardia, El Comercio, El Diario Vasco, El Mundo, El Periódico, o Marca ponen en marcha sus ediciones digitales. Un año más tarde lo hacía El País. Para enero del año 2000, el número de periódicos españoles de información general con ediciones digitales se situaba ya en 68 (Díaz Nosty, 2000: 135) e incluso habían aparecido los primeros nativos digitales, algunos de ellos como Estrella Digital, nacido en 1998, con vocación de prensa de alcance nacional.

El desarrollo de los diarios online discurre en paralelo con la decadencia de la prensa en papel. La difusión de esta última en España a partir de 2005 inicia un sostenido descenso, reproduciendo un fenómeno que, según AEDE (2003), ya se estaba produciendo en la Unión Europea desde la segunda mitad de los años 90 del siglo pasado. De una difusión global superior a los 4 millones diarios de ejemplares en el año 2000, se pasa a 1,5 millones en 2019; lo que supone un descenso en las ventas del 64\%. Este desplome de la circulación ha afectado especialmente a la prensa de ámbito estatal. Cabeceras como El País, El Mundo o Abc vendían en 2019 prácticamente una cuarta parte de los 
ejemplares que distribuían a principios del presente siglo. En el caso de la prensa regional, la caída no es tan dramática pero también se sitúa, en la mayor parte de los casos, por encima del $50 \%$. En la tabla 3 puede observarse una comparativa de audiencia entre los diez diarios impresos con mayor número de lectores y los diez digitales con mayor número de usuarios únicos.

Tabla 3. Audiencia de los diarios impresos y digitales (en miles)

\begin{tabular}{|l|r|l|r|}
\hline \multicolumn{1}{|c|}{ Impresos } & EGM $\mathbf{2 0 2 0}$ & \multicolumn{1}{c|}{ Digitales } & ComScore (abril 2020) \\
\hline Marca & 1.596 & abc.es & 27.977 \\
\hline El País & 1.004 & lavanguardia.com & 26.600 \\
\hline As & 750 & elmundo.es & 26.162 \\
\hline El Mundo & 657 & elpais.com & 26.055 \\
\hline 20 Minutos & 572 & 20minutos.es & 22.662 \\
\hline La Vanguardia & 532 & elespanol.com & 22.422 \\
\hline La Voz de Galicia & 492 & elconfidencial.com & 21.975 \\
\hline Abc & 444 & eldiario.es & 16.794 \\
\hline Mundo Deportivo & 367 & okdiario.com & 16.315 \\
\hline El Periódico & 362 & larazon.es & 13.459 \\
\hline
\end{tabular}

Fuente: OJD y ComScore. Elaboración propia.

Al preocupante dato del desplome de la difusión, hay que añadir el recorte paulatino de la inversión publicitaria en prensa, según los datos de Infoadex, mientras iba creciendo la dirigida a Internet. Si en 2000 los diarios atraían publicidad por valor de 1.689 millones de euros, en 2019 esta cifra se quedaba en 485 millones. En 2012, por primera vez, la inversión publicitaria en Internet $(880,5$ millones) superaba a la de los diarios $(766,3)$ iniciando una tendencia que se ha acentuado año a año.

A la vista de estos datos, no es de extrañar que las modificaciones formales de la prensa española en el nuevo siglo no hayan alcanzado la espectacularidad y el dinamismo de épocas anteriores. De todas formas, cabe recordar algunos de los rediseños que tuvieron lugar durante la primera década como, por ejemplo, los realizados en 2007 por El País y La Vanguardia; o en 2009 por El Mundo y por los diarios regionales del Grupo Vocento (El Correo, El Diario Vasco, El Norte de Castilla...). Precisamente en 2007 vio la luz el periódico Público diseñado por el estudio de Antoni Cases y cuya maqueta ofrecía, como señalaba Sabés Turmo (2008: 135) una imagen de ligereza. En 2012, esta cabecera dejó de editarse en papel y mantuvo únicamente su edición web.

El objetivo de este artículo es analizar el diseño de la prensa española durante la última década y los posibles cambios que se han producido a lo largo de la misma. 


\section{Estudios previos}

Hace ya tiempo que la importancia del diseño dentro del periodismo moderno fue destacada por diferentes autores. Así, Rehe (1990: 9) explica que el diseño y el contenido de la noticia se deben ofrecer de modo que formen un conjunto unitario. Vilmos y Aladár (1986: 357) apuntan al papel del diseño para que el lector reciba sin esfuerzo gran cantidad de información. Canga (1994: 23) recuerda el papel del diseño en la jerarquización de las informaciones. Para Lallana (2000: 15), el diseño consiste en organizar la información para que el lector discurra sobre ella de forma eficaz. Zorrilla define al diseñador como un «periodista especializado en la materialidad de la información» $(1997,24)$.

Hutt y James (1989: 9) entienden que, si bien el contenido es el factor más importante en el éxito de un diario, la presentación es una parte integral de dicho factor. Para Giles y Hodgson, el diseño guía sutilmente al lector a través del contenido de las páginas, «combinando comodidad visual y familiaridad con una cantidad razonable de sorpresa» (2000: 1). Por su parte, Moen (1989) confiaba en que el diseño fuese la mejor esperanza para que los periódicos se convirtiesen en medios "visuales". Una idea en la que también incide Álvarez Marcos, al comentar que «los periódicos actuales se conciben no sólo para ser leídos, sino también para ser vistos (ojeados): diarios en los que los lectores son simultáneamente espectadores» (2017: 70).

González Díez y Pérez Cuadrado sitúan como primer objetivo del diseño periodístico «comunicar la información de forma clara y precisa buscando la máxima legibilidad» (2002: 40). En una visión más contemporánea de dicho concepto, González Díez, Puebla Martínez y Pérez Cuadrado (2018) sitúan el diseño periodístico de forma implícita en la actual narrativa transmediática.

Suárez Carballo, a la hora de analizar las funciones del diseño periodístico moderno, alude a que «la magnitud y relevancia que ha adquirido la vertiente visual en la comunicación de masas inciden directamente en la propia definición del diseño periodístico, que pasa a convertirse en una disciplina polifacética con múltiples implicaciones y objetivos [...]» (2008: 31). López Alonso se refiere a la nueva situación creada con la coexistencia entre periodismo impreso y digital, lo que convertiría al diseño periodístico en un valor para la «supervivencia y adaptación a la nueva situación» para la prensa en papel (2013: 12).

Para López Hidalgo, la función estética del diseño periodístico «se entrecruza e hibrida con su función informativa e interpretativa y, como consecuencia, el resultado es un nuevo lenguaje que nos muestra un mundo ya descodificado» (2017: 19). Martínez-Fresneda, no obstante, advierte que «un uso 
premeditado del diseño periodístico puede afectar claramente al derecho a una información veraz [...]» (2008: 184).

En las últimas dos décadas se han publicado diversos estudios en relación con el diseño periodístico de la prensa española. Vizcaíno-Laorga y Jiménez-Ruesta en su estudio sobre los rediseños del siglo XXI apuntan a la relación entre difusión y rediseño, pero únicamente hasta 2008: «El rediseño, por tanto, parece funcionar en condiciones de normalidad económica, pero no en situaciones de crisis manifiesta [...]» (2018: 133). Subiela-Hernández y Gómez-Company (2018) han investigado las ventajas del diseño discursivo para una mejor comprensión de la información.

Del Olmo y Parrat (2011) abordaron las diferencias formales entre la prensa gratuita y la de pago, subrayando las desigualdades existentes entre ambos modelos en lo referente a la tipografía y al color. El diseño de los diarios gratuitos también había sido estudiado por González Díez y Pérez Cuadrado (2007).

Entre los estudios de caso, además del ya citado de Sabés Turmo (2008) sobre el resideño de La Vanguardia y el nacimiento de Público, se encuentra el realizado por Mejía Chiang (2017) sobre el arrevistamiento en las portadas de este último diario, y el llevado a cabo por González Díez et al. (2015) sobre la influencia que las decisiones adoptadas en torno al diseño periodístico pudieron tener en la breve vida (cuatro meses en 1991) del diario popular Claro. Franco Álvarez (2004) recuerda la influencia del modelo representado por El País en la prensa española en su estudio sobre las portadas del 11-S y el 11-M. Habría que aludir asimismo a la historia gráfica de la prensa diaria española, entre 1758 y 1976, elaborada por Vílchez de Arribas (2011).

Por último, en el ámbito de la tipografía utilizada por la prensa, podemos destacar el detallado estudio realizado por Fernández González (2017), quien analizó las fuentes empleadas por 94 diarios impresos españoles durante 2016. Este autor destaca el hecho de que la tipografía de encargo se encuentre asentada en los diarios españoles y que un buen número de cabeceras emplee fuentes personalizadas para su uso exclusivo (2017: 72-73).

\section{Objetivos e hipótesis}

Como ya se ha señalado, el objetivo de este artículo es analizar los posibles cambios acontecidos en los principales diarios españoles durante la última década (2010-2020), comparándolos con los realizados en años precedentes. Las hipótesis que se plantean en este trabajo son las siguientes: 
- La crisis de los diarios en papel, con una marcada caída en las ventas y en la inversión publicitaria, se ha reflejado en un menor número de rediseños durante la última década.

- Los rediseños no han tenido la espectacularidad ni el calado de los que se realizaron en décadas precedentes.

- Los diarios siguen manteniendo muchas de las características visuales de principios de siglo (utilización de color, formatos de lectura rápida, infografía, secciones de servicios).

-Frente a la omnipresencia de la Times y la Helvética de épocas anteriores, los diarios han reforzado su identidad visual mediante el empleo de tipografías diferenciadas.

\section{Metodología}

A la hora de analizar los posibles cambios formales en los diarios seleccionados en la muestra, se han tenido en cuenta las propuestas metodológicas descritas en otros estudios, algunas de ellas con aportaciones desde otros campos, como el de la retórica visual (Subiela, 2018 y Subiela y Gobantes Bilbao, 2010), o el de la Teoría de la imagen (Suárez, Martín y No, 2014). Estos últimos autores abogan por impulsar una consideración multidisciplinar en el estudio de la eficacia del diseño gráfico, implicando a ámbitos como la psicología, la sociología o la filosofía. Suárez entiende que la psicología de la percepción y la psicología cognitiva, «constituyen campos naturalmente vinculados al estudio del diseño de diarios, esenciales para comprender de manera global el proceso comunicativo y la eficacia de la forma en el mensaje periodístico» (2008: 137).

Otros autores como Sabés Turmo (2008) recurren al análisis de contenido cuantitativo en la línea de los planteamientos de Berelson (1952) o Krippendorff (1990). Esta misma técnica del análisis de contenido cuantitativo ha sido también aplicada por autores como Puebla Martínez, González Díez y Pérez Cuadrado (2015) en su investigación sobre las cabeceras de la prensa deportiva española.

En el presente texto se han analizado seis de los siete diarios de información general con mayor difusión en 2019, según datos de OJD. Se trata de tres cabeceras de ámbito nacional editadas en Madrid, como El País, El Mundo y $A b c$; las dos principales de Barcelona, La Vanguardia y El Periódico, y una representante de la prensa regional, como El Correo. Aunque en 2019, otro diario regional, como $\mathrm{La} \mathrm{Voz} \mathrm{de} \mathrm{Galicia,} \mathrm{superaba} \mathrm{ligeramente} \mathrm{las} \mathrm{ventas} \mathrm{de} \mathrm{El}$ Correo, se ha optado por este último, ya que su modelo se ve reflejado en el resto de las 11 cabeceras provinciales y regionales del Grupo Vocento. 
En el estudio se han repasado los últimos rediseños y se ha profundizado en la propuesta formal de cada rotativo en 2020. Para ello se ha recurrido a lo que autores como Gaitán y Piñuel (1998) denominan «observación directa».

\section{Resultados}

\subsection{El País}

El País nació en Madrid el 4 de mayo de 1976 y su maqueta original fue obra de Reinhard Gäde. En un momento en que la prensa española, recién salida del franquismo, adolecía en muchos casos de una obsolescencia tecnológica, la aparición de este periódico supuso el inicio de una nueva forma de hacer periodismo en España. En su alzado se recogían secciones novedosas hasta entonces, como Sociedad o Cultura. En este sentido, Vílchez asegura que, este diario «ha marcado un antes y un después en la moderna historia de la prensa diaria española» (2007: 24).

El País plantea una morfología ordenada, en la que la letra Times es omnipresente, salvo en los titulares de Deportes - Tecno- y en los pies de foto - Newton- La cursiva pasa a convertirse en el estilo tipográfico de los titulares de opinión. Gäde impuso una serie de normas de obligado cumplimiento, como la imposibilidad de que una foto se interpusiera entre el titular y el inicio del texto o la conveniencia de no interrumpir el texto, mediante sumarios u otros elementos. Cada página llevaba habitualmente una única entradilla y una foto horizontal a tres columnas o vertical a dos. Dado que esta cabecera salió impresa en offset, la calidad de estas imágenes era atípicamente buena en una época en la que la mayoría de los diarios conservaban sus antiguas rotativas tipográficas.

En contraste con los grandes formatos que todavía sobrevivían en España - standard o berlinés-, El País optó por las dimensiones de un tabloide y una pauta de 5 columnas; lo que a la larga se convertiría en el modelo a seguir por el resto de las cabeceras. Según explicaba el propio Gäde, se planteaba un diario con diferentes velocidades de lectura: «Queríamos que el periódico se leyese en diez minutos y después tuvieras la opción de volver a lo que te interesara» (2007: 38).

En sus más de 40 años de vida, El País ha sufrido varios rediseños, pero tras todos ellos siguen siendo identificables las líneas maestras de su maqueta original. Desde un punto de vista visual, quizá el cambio más llamativo se produjo el 27 de septiembre de 1998, fecha en la que empezó a incorporar color a la portada y a la contraportada. Tras las modificaciones de octubre de 2001, el color pasó a utilizarse de forma diaria. 
Los dos últimos rediseños tuvieron lugar en 2007 y 2015. En el del 21 de octubre de 2007 intervinieron los diseñadores británicos Terry Watson y Ally Palmer y, en el mismo, se llevó a cabo una reordenación del alzado del diario, agrupando en la primera parte las secciones más "informativas", como Internacional, Nacional y Economía; y dejando para la parte final, tras Opinión, las de Sociedad, Cultura y Deporte.

Imagen 1. Portadas de El País en 2010 (izquierda) y 2020 (derecha)
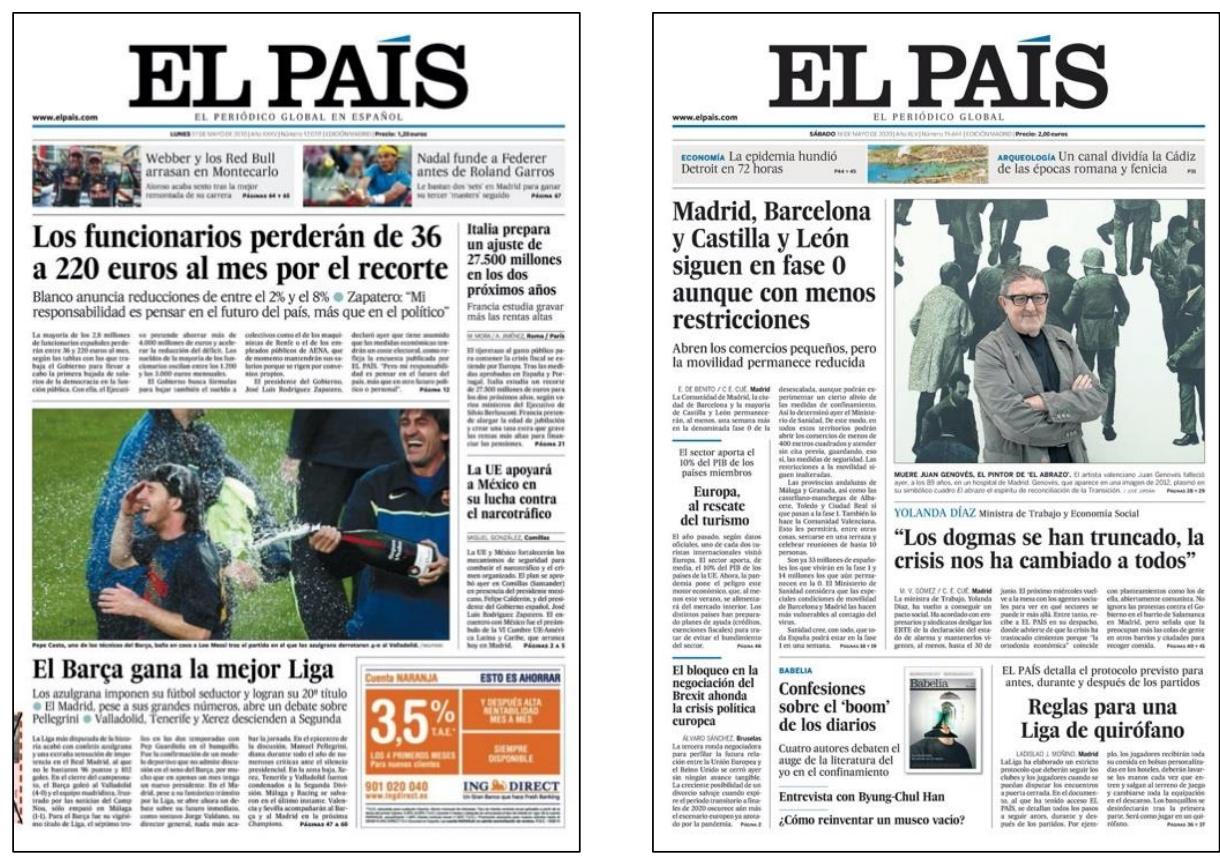

En la portada se modificó levemente la cabecera con la inclusión de la tilde en la í de El País y se sustituyó el lema de "Diario independiente de la mañana" por el de "El periódico global en español" ("El periódico global" desde el 27/11/2013, coincidiendo con el lanzamiento de su edición digital en portugués). Por otro lado, se incorporó diariamente un "balcón" debajo del logotipo con llamadas a los temas más destacados del día. Hasta entonces, este recurso del balcón o friso, únicamente se utilizaba los domingos.

Tanto en la portada como en las páginas interiores desaparecían las entradillas en negrita, otra de las señas de identidad de esta publicación desde su inicio. Entre los elementos identificativos que se modificaban estaba la tipografía, El País decía adiós a la Times (en versión Millenium en la época anterior) y pasaba a utilizar la Majerit, diseñada para este medio por el tipógrafo portugués 
Mario Feliciano. En el suplemento del Domingo la Madrid de los titulares dejaba paso a la Arnhem y, en los textos, la Utopía sustituía a la Miller.

La importancia de las familias, como es el caso de la Majerit, expresamente creadas para su utilización en un determinado diario y su relevancia de cara a la renovación tipográfica de la prensa española, fue una cuestión analizada por Fernández (2016). Se da la circunstancia de que ya en 1990, tal y como recuerda Curtis (2007), el diario El Sol abonó el equivalente a 24.000 euros por el uso en exclusiva durante dos años de la Grotesque.

El 11 de mayo de 2015 veía la luz un nuevo rediseño de El País — «una puesta al día», según su director de entonces Antonio Caño (El País, 10/05/2015) - En la portada, desaparecían los frisos y en las páginas interiores se recuperaban las entradillas en negrita para las informaciones, uno de los símbolos de la etapa anterior. El alzado se renovaba. Ahora, a Internacional le seguía Opinión, tras la que se situaba España, Ciencia y Tecnología, Cultura, Deportes, Economía y Gente. Como novedad, aparece una Página 2 dedicada a la opinión.

La tipografía se asienta fundamentalmente en la Majerit, salvo en los titulares de Deportes que se componen en Benton, una fuente palo seco. Los suplementos se renuevan y Domingo pasa a denominarse "Ideas".

En 2020, El País continuaba manteniendo los rasgos morfológicos de su último rediseño, con algunas pequeñas modificaciones. Así, en su primera página, desde el 9 de septiembre de 2018 ha recuperado el balcón diario bajo el logotipo, habitual hasta 2015. Ese mismo día, retomaba la sección de Sociedad, desaparecida tras el último rediseño.

El 16 de abril de 2017 se eliminaba la denominada «Página 2» una sección de opinión sobre cuestiones de actualidad y su lugar pasaba a convertirse en el inicio de la sección de Internacional.

Como ya se ha señalado, el rotativo sigue manteniendo las líneas maestras de su identidad visual. Se continúa apostando por la uniformidad tipográfica, ahora en torno a la Majerit, salvo en los titulares de Deportes y en los suplementos. Los titulares pueden acompañarse, en función del género, la sección o el lugar en la página, de antetítulos o de subtítulos. Se mantienen las entradillas en negrita y la cursiva sigue siendo sinónimo de titular de opinión. La negrita se emplea también en los despieces o textos de apoyo. Tanto los filetes verticales como horizontales (en versiones muy finas) son habituales en las portadas, pero más excepcionales en páginas interiores, donde son más frecuentes los corondeles ciegos. Ladillos y sumarios (que intentan nuevamente no interrumpir la continuidad del texto) están presentes a lo largo del diario. La sensación visual es la existencia de una amplia gama de recursos para la composición de la página. 


\subsection{La Vanguardia}

La Vanguardia es una de las publicaciones decanas de la prensa española, ya que nació en Barcelona el 1 de enero de 1881. Durante la década de los 60 del siglo pasado el periódico catalán ya introducía color en sus portadas dominicales, utilizando para ello la impresión en huecograbado. En los 80, el diario afronta una importante renovación tecnológica que conlleva el abandono de la impresión tipográfica y su sustitución por el offset. Como parte de este proceso de modernización, se llevó a cabo el rediseño en profundidad de un periódico que en aquella época utilizaba un formato standard $(320 \times 490 \mathrm{~mm})$ y una pauta de 6 columnas.

El nuevo diseño, obra del estudio neoyorquino de Walter Bernard y Milton Glaser, vio la luz el 3 de octubre de 1989 y fue uno de los más llamativos de la prensa española moderna por el alcance de los cambios efectuados. A pesar de los rediseños y retoques que se han aplicado al diario en las últimas décadas, sus líneas maestras siguen siendo reconocibles, igual que ocurre con la maqueta inicial de Gäde en El País. La Vanguardia redujo el formato $(310 \times 450 \mathrm{~mm})$, apostó por un énfasis horizontal y por la división de los contenidos en tres bloques: el diario propiamente dicho, La Revista (reportajes y temas de servicios) y un suplemento temático. En la tipografía se empleaba fundamentalmente la Times aunque la cursiva se utilizaba en los titulares informativos para crear contraste, algo que venía siendo habitual en la prensa norteamericana. Como segunda familia para cintillos, fichas técnicas, fotonoticias, etc., se recurría a la Futura.

18 años después de este rediseño, La Vanguardia realizó una nueva transformación formal que se materializó el 2 de octubre de 2007. El equipo de rediseño estuvo encabezado por Pablo Martín, del estudio Gráfica. A fin de adaptarse a las nuevas rotativas adquiridas por la empresa editora, el periódico redujo el formato del berlinés anterior a unas medidas de $289 \times 410 \mathrm{~mm}$, más propias de los tabloides al uso en España.

También se produjeron cambios en la tipografía, ya que la omnipresente Times de la etapa anterior dejó su sitio a otra romana más actual como la Mercury, una familia diseñada por Jonathan Hoefler y Tobias Frere-Jones en 1997. Al mismo tiempo, la san serif Futura pasaba a ser sustituida por la Taz, otra fuente palo seco.

Aunque el propio diseñador Pablo Martín, en palabras recogidas por Sabés Turmo (2008: 121), consideraba el rediseño más un lifting que una modificación en profundidad; para este último autor «desde un punto de vista estético, se trata de un cambio con muchos matices». En la nueva portada, destacaba un ancho friso de color, debajo del logotipo, que sirve para adelantar algunos de los temas de las páginas interiores. Por otra parte, el periódico 
incorporaba nuevos suplementos temáticos como "Estilo de vida" (sábados), "Casas" y "Empleo" (domingo).

Imagen 2. Portadas de La Vanguardia en 2010 (izquierda) y 2020 (derecha)

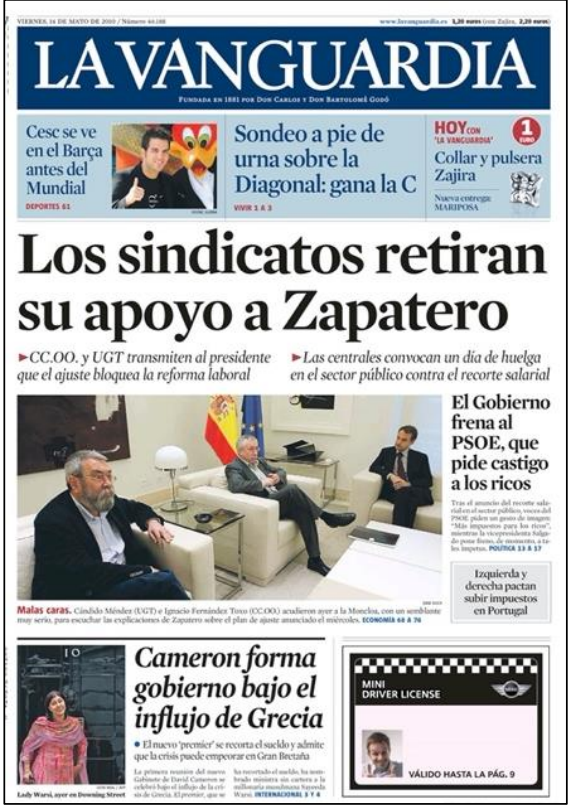

\section{LAVANGUARDIA}

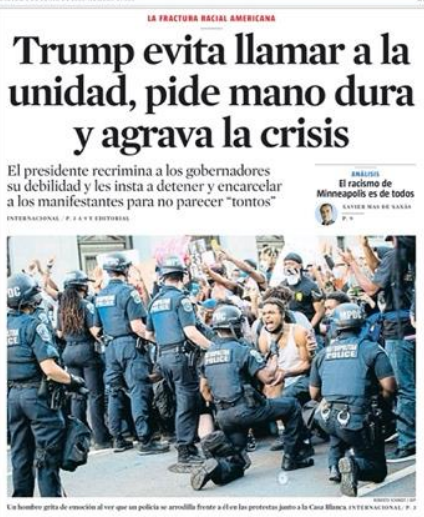

Trump evita llamar a la estado de arma y la renta minim dividen a dad, pide mano dura a derecha

domingo fue el primer día sin muertos por el virus en España en toda la epidemia

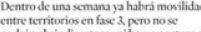

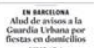

La distancia
de más de un de más de un
metro reduce cl contagio podrin abrir discotecess nit tans nocturn

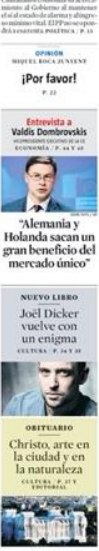

El 23 de julio de 2019, la portada de La Vanguardia mostraba algunas modificaciones que se mantienen hasta la actualidad, la más destacada es la desaparición del friso junto a la cabecera. Los sumarios, que se situaban en dicha zona, se colocan ahora también sobre un fondo de color, bien "en chimenea" en la parte inferior de la columna derecha o en el faldón inferior de la página. Por otro lado, se comienza a recuadrar la noticia principal de la primera página, un recurso prácticamente abandonado desde el rediseño de 1989.

En 2020, La Vanguardia contaba con las siguientes secciones: Portada, La Segunda (Opinión sobre temas de actualidad), Internacional, Política, Opinión, Sociedad, Cuadernillo "Vivir" (temas locales y de servicios), Cultura, Cartelera, Deportes, Economía y La Contra. Los viernes publica el suplemento "Quèfem?", dedicado al ocio, los sábados "Culturas", y los domingos "Dinero". El diario mantiene en sus páginas interiores los filetes horizontales y sigue utilizando la cursiva en determinados titulares informativos e interpretativos; no así en la opinión. Los sumarios y los textos de apoyo continúan "interrum- 
piendo" los textos principales, manteniendo la filosofía de las "áreas de descanso visual" del rediseño de 1989.

\subsection{El Mundo}

El Mundo es otro de los exponentes de las nuevas propuestas formales aparecidas en la prensa española a finales del siglo XX. Su primer ejemplar se editaba en Madrid el 23 de octubre de 1989. Su maqueta fue obra de su director de arte, Carmelo G. Caderot, quien apostó por un estilo novedoso en aquel momento y en el que se desarrollaba la idea de la doble velocidad de lectura y de que se pudiese acceder a la página de formas diversas.

Junto a los formatos de lectura rápida - antetítulos o subtítulos en "flash", despieces, etc.-, El Mundo rompía también con la homogeneidad tipográfica representada por El País. Así, el titular principal de cada página se componía en Helvética y los secundarios en Times, letra que también se usaba en el texto.

El 9 de octubre de 1998, la publicación presentó el primero de sus rediseños, que conllevó la incorporación diaria del color en la portada y contraportada. También se retocó la tipografía. En la mancheta, la rotundidad de la Rockwell dejó pasó a la Madison, familia que empezó a emplearse en los titulares secundarios. Para los titulares principales se utilizó una versión más condensada de la Helvética. En los textos, la Times fue sustituida por la Imperial, una fuente diseñada por Edwin W. Shar en los años 30 del siglo pasado.

Este periódico presentó un nuevo rediseño el 11 de enero de 2009. Según explicaba ese mismo día el director de arte, Carmelo G. Caderot, la premisa del cambio «es un periódico más potente gráficamente, más visual, fácil y digerible, pero sin restarle información» (El Mundo, 11/01/2009).

Junto a la mayor presencia gráfica, también se modificó la tipografía. En todos los titulares, salvo en Deportes, se recurrió a la familia Valencia (romana), lo que ponía fin al empleo del contraste entre la palo seco de la noticia que abría las secciones y las romanas del resto de las noticias. En Deportes se optó por la Neo Sans, diseñada por Sebastian Lester en 2004. En los textos se mantenía la Imperial, de la etapa anterior, pero con el cuerpo incrementado en medio punto.

El 20 de octubre de 2014, coincidiendo con los 25 años de vida del periódico se materializó un nuevo rediseño. Según Rodrigo Sánchez, director de Arte, el nuevo diseño destaca por su versatilidad, «se adapta a las necesidades informativas del día. La portada y las páginas se adaptan a las noticias y no al revés» (El Mundo, 19/10/2014). 
Imagen 3. Portadas de EI Mundo en 2010 (izquierda) y 2020 (derecha)
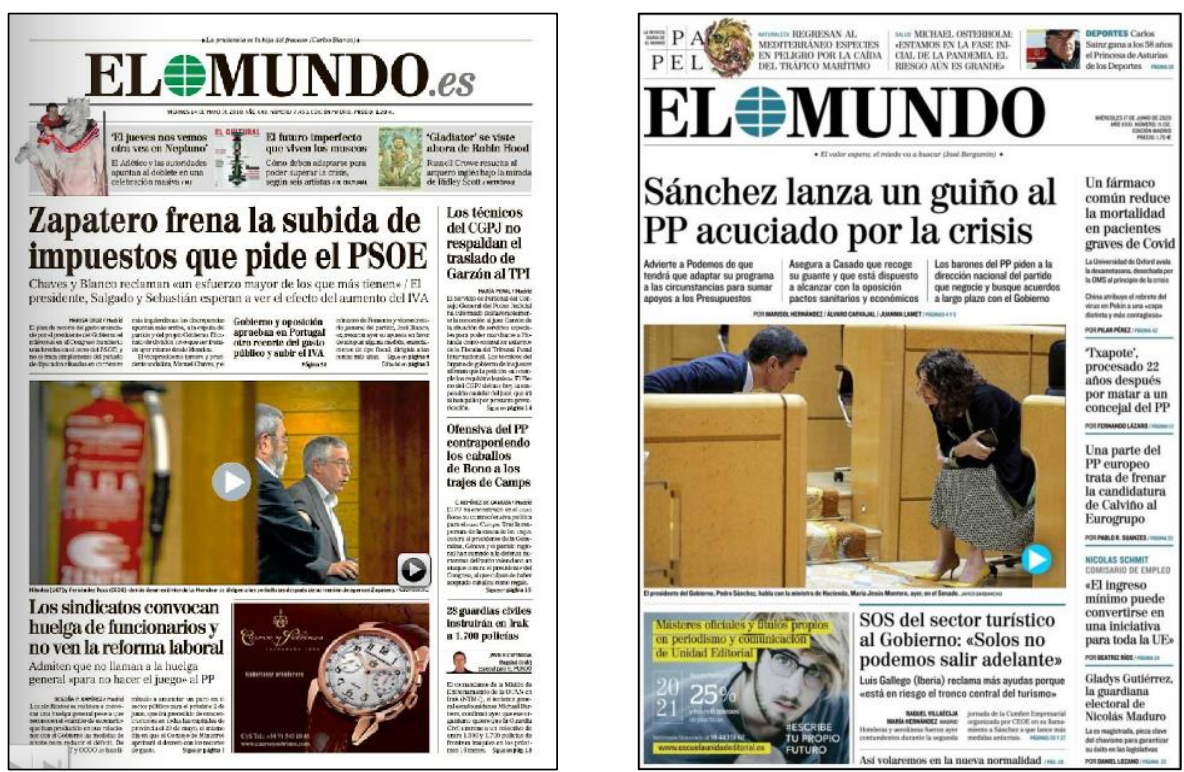

En la nueva portada, la mancheta aparece alineada a la izquierda y el globo terráqueo, icono de la publicación desde su nacimiento, torna cromáticamente hacia un verde azulado, tonalidad que se reproduce en la tipografía de las secciones, filetes y tramas. Desaparece el balcón bajo el logotipo, pero se aprovecha, a modo de friso, la parte superior del mismo para incluir una serie de llamadas. Como explica Mario Benito (2017), en este rediseño «se produce una limpieza tipográfica reduciendo el peso de los títulos que se componen en sus mismas tipografías, pero en su variante redonda en vez de en negrita y se incorpora para diferenciar distintas secciones el versátil y poderoso tipo de letra Knockout».

Asimismo, se reforzaba el diseño del bloque EM2, que agrupa los temas de Sociedad, Ciencia, Cultura y Comunicación. Sin embargo, un año después, en septiembre de 2015, la parte final del diario pasaba a estar ocupada por la sección de Cultura y EM2 comenzaba a dedicarse fundamentalmente a temas de Sociedad, resituándose entre la sección de Mundo y la de Economía. En noviembre de 2017, EM2 retomaba nuevamente su contenido anterior. Finalmente, desde el 1 de noviembre de 2017, la sección Papel, anterior suplemento dominical y ahora definido como "La revista diaria de El Mundo", agrupa muchos de los contenidos de EM2. 
En la actualidad, El Mundo mantiene las siguientes secciones: Portada, Opinión, España, Salud, Otras voces, Mundo, Economía, Deportes, Papel y Contraportada. Papel cuenta con un diseño propio, arrevistado, con los titulares en versales, una pauta de 6 columnas y los textos alineados a la izquierda. Estas características también se conservan en el suplemento DXT.

Por último, el 15 de marzo de 2020 el periódico incluyó una serie de modificaciones en su edición dominical. La más llamativa es el empleo del tamaño sábana para la portada. Esta edición recuerda a un magazine, con grandes fotografías, titulares en versales, predominio de los géneros interpretativos y un tema central. En dicha edición se incluyen la sección de reporterismo "Crónica" y el deportivo DXT.

Cabe recordar que en los premios ÑH19, organizados por el capítulo español de la Society for News Design (SND-E) y la SND Sudamérica, El Mundo recibió un Reconocimiento Especial del Jurado por la creatividad de la sección diaria "Papel".

\subsection{Abc}

$A b c$ nació como publicación en Madrid el 1 de enero 1903, si bien hasta el 1 de junio de 1905 no adquirió una periodicidad diaria. Durante prácticamente todo el siglo $\mathrm{XX}, A b c$ mantuvo las principales características formales de sus inicios: formato arrevistado ( $23 \times 32$ centímetros, aproximadamente), presencia de una estructura exterior que envolvía el resto de las páginas y que concentraba el peso gráfico del mismo, páginas interiores sin apenas fotografías. Este esquema conllevaba la existencia de 2 portadas, una visual y otra textual. Durante años ese envoltorio exterior gráfico se imprimía en huecograbado, mientras que las páginas interiores se tiraban en rotativas tipográficas. El cambio a la impresión offset en junio de 1989 tampoco supuso un cambio sustancial en este esquema. Otra de las señas de identidad de esta cabecera ha residido en el grapado de sus páginas, algo atípico en la prensa española.

El diario presentó un rediseño de cierto calado el 16 de julio de 1999, obra del estudio de Walter Bernard y Milton Glaser. Se incrementó ligeramente el formato $(26 \times 35,5$ centímetros), se retocó la mancheta y se optó por una pauta de 4 columnas. En la tipografía la Bureau Grotesque One Five sustituyó en los titulares principales a la Century, mientras que en los textos la Nimrod ocupó el lugar de la Clarion.

En 2001, la editora de $A b c$, Prensa Española, se fusionó con el Grupo Correo. El nuevo entramado pasaría a denominarse Vocento en 2003. Precisamente, tras esta fusión, $A b c$ sufrió en 2002 una nueva remodelación coordinada por Alberto Torregrosa, hasta entonces asesor de diseño del Grupo Correo. 
Los principales cambios consistieron en ciertos retoques tipográficos (tipos más anchos en los titulares) y en el centrado de la mancheta.

Imagen 4. Portadas de $A b c$ en 2010 (izquierda) y 2020 (derecha)
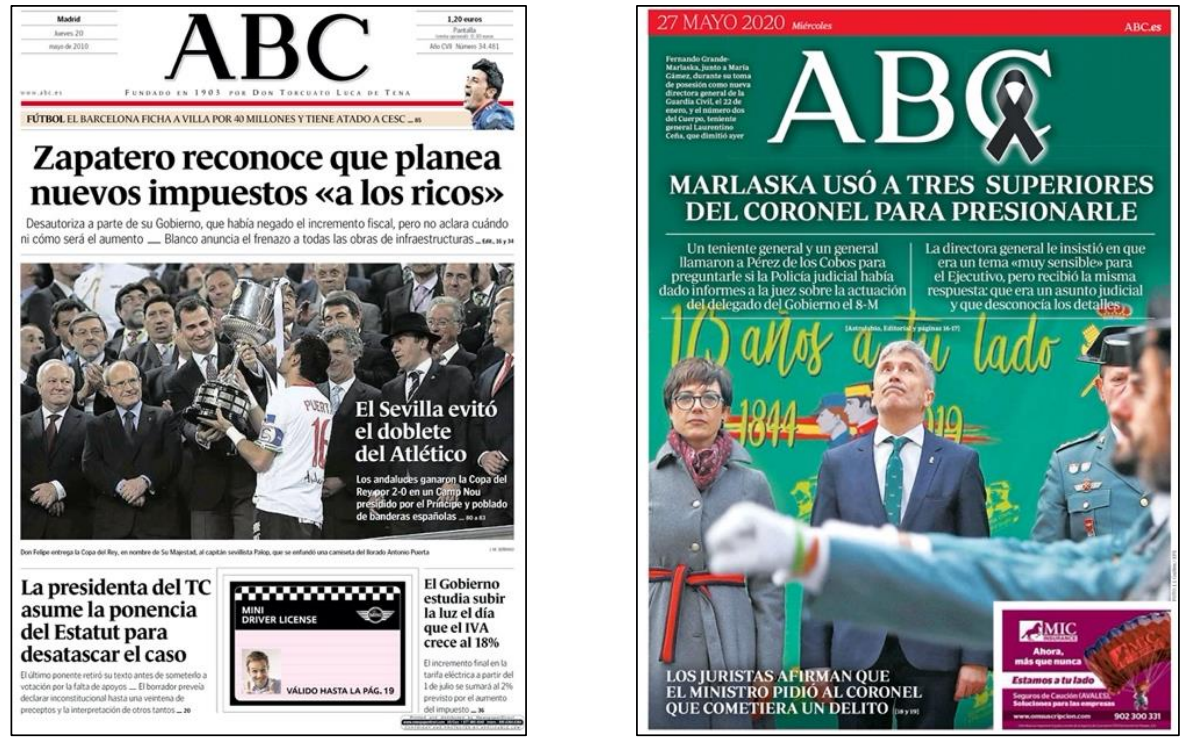

El 11 de junio de 2010, $A b c$ volvía a presentar una serie de modificaciones, tras un rediseño liderado por Alfredo Triviño. La principal novedad consistía en el uso de una tipografía diseñada específicamente para los diferentes elementos del periódico por el tipógrafo argentino Eduardo Manso, que sería más tarde comercializada con el nombre de "Periódico". Según se señala en la web del estudio de Manso ${ }^{1}$, se trata de una fuente basada en la tipografía española de la segunda mitad del siglo XVIII. Por otro lado, la publicación retomaba la pauta de cuatro columnas. Asimismo, se llevó a cabo una modificación del logotipo de este medio. Este logotipo sufrió otro retoque, el 16 de noviembre de 2011, al eliminarse el perfilado del mismo.

En la actualidad, $A b c$ sigue manteniendo unas dimensiones $(26,5 \times 35$ $\mathrm{cm}$ ) algo más reducidas que la mayoría de los tabloides españoles y continúa estando grapado. Su portada responde a lo que García denominaba «estilo tabloide cartel» (1984: 52). Una gran foto ocupa la práctica totalidad de la página y la mancheta se sitúa "pisando" dicha imagen. No es infrecuente que esta portada tenga un carácter monográfico, lo que hace que "La Dos" conten- 
ga una segunda portada tipográfica más convencional con un titular de apertura y una serie de titulares secundarios con los otros temas destacados que el lector encontrará en el interior. Esta doble primera página supone mantener una tradición asentada en el diario desde la época en que se utilizaba la impresión en huecograbado y tipografía.

Tras la portada se sitúa la página de opinión conocida como "La Tercera" y la plana editorial. A continuación, viene "Enfoque", un repaso a la actualidad gráfica del día, Opinión, España, Internacional, Economía, Sociedad, Cultura, Deportes, Agenda, Gentestilo\&TV y la contraportada.

El periódico continúa empleando una pauta de cuatro columnas. $A b c$ es otro de los diarios que no recurre a la cursiva para los titulares de opinión y en los textos utiliza tanto ladillos como sumarios. Lo habitual es que emplee subtítulos en las informaciones $\mathrm{y}$, puntualmente, antetítulos en géneros interpretativos. El diseño de $A b c$ obtuvo el reconocimiento en la edición de 2017 del European Newspaper Award, dentro de la categoría de "News Pages".

\subsection{El Correo}

El Correo, de Bilbao, es la cabecera con mayor difusión del grupo de diarios regionales del Grupo Vocento que agrupa también a El Diario Vasco de San Sebastián, El Diario Montañés de Santander, La Rioja de Logroño, El Comercio de Gijón, El Norte de Castilla de Valladolid, Hoy de Badajoz, Sur de Málaga, Ideal de Granada, La Voz de Cádiz, La Verdad de Murcia y Las Provincias de Valencia.

El Correo nació en la capital vizcaína, el 1 de mayo de 1910, con el nombre de El Pueblo Vasco. Durante la guerra civil y tras la entrada de las tropas de Franco en Bilbao, la publicación se fusionó con El Correo Español, publicación aparecida en 1937. El nuevo diario nacido de esta unión vería la luz con la denominación de El Correo Español-El Pueblo Vasco el 13 de abril de 1938. A lo largo de su historia, este rotativo ha sufrido diversos rediseños. En 1965, abandonó el formato sábana y optó por el tabloide. En 1982, sustituyó el sistema tipográfico de impresión por el offset, lo que conllevó nuevos cambios en su aspecto. En 1988, decide utilizar una pauta de cinco columnas en lugar de la de seis y se deja de emplear la Helvética en titulares y texto, siendo sustituida por la Geneva y la Times, respectivamente.

En junio de 1991, bajo la supervisión Alberto Torregrosa y Aurelio Garrote, se introdujeron nuevos retoques, como fue el empleo de la familia Swiss 721 en la titulación y la Century en los textos. Dos años después, llegó otra remodelación que conllevó la modificación de la cabecera y la incorporación del color, así como la utilización de la Franklin Gothic en la titulación. 
El Correo protagonizó un espectacular rediseño en 2000, apostando por un modelo en la línea de lo que autoras como Diezhandino (1994) denominan "diario de servicio". Según explicaba el asesor de diseño del Grupo, Alberto Torregrosa, los lectores «demandaban que el periódico fuera de utilidad, que les diera pautas para poderlo usar» (2007: 164). El nuevo diseño vio la luz el 22 de marzo de 2000 y, para el mismo, la empresa contó con el diseñador escocés Ally Palmer. El alzado del periódico se dividía en cuatro grandes áreas: "Ciudadanos", "Actualidad", "Deportes" y "Vivir", y se apostaba por formatos de doble velocidad de lectura. En la tipografía se optaba por la Cívica para los titulares y la Nimrod para los textos.

Imagen 5. Portadas de El Correo en 2010 (izquierda) y 2020 (derecha)

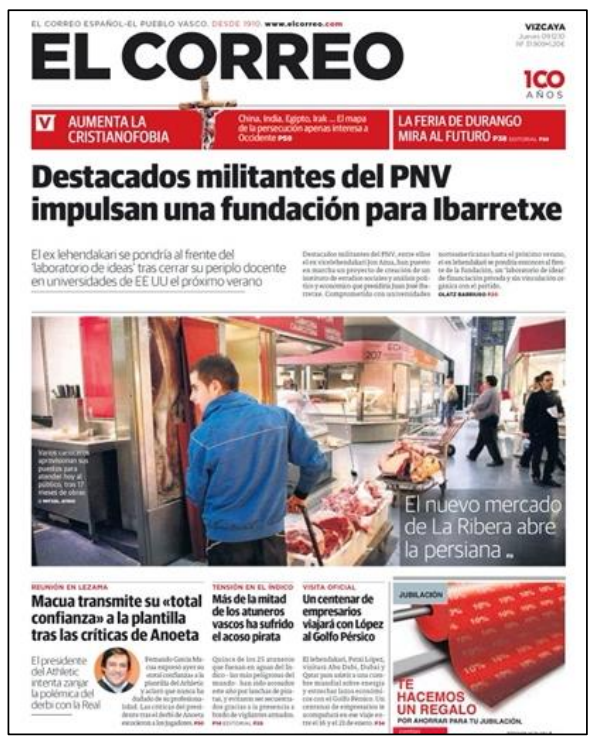

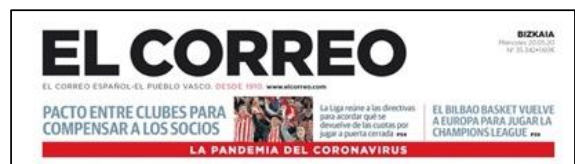

Euskadi pide al Gobierno una fase 2 con aforos a la mitad en bares y comercios

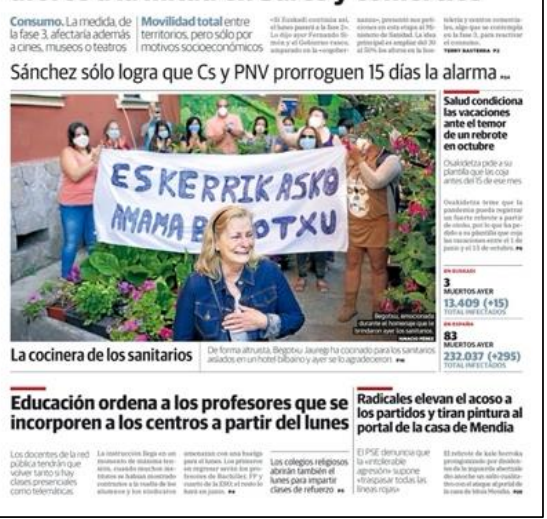

El 27 de noviembre de 2009, el Grupo Vocento llevó a cabo una nueva operación de rediseño a fin de homogeneizar las características formales de sus diarios regionales. Entre los cambios, se pasaba a emplear la Guardian Sans en los titulares y la Brioni en los textos. Asimismo, se creaba un nuevo suplemento, diario "V", común para las distintas cabeceras.

El último de los rediseños de El Correo se produjo el 11 de febrero de 2020. En la tipografía se pasa a utilizar la IBM Plex Serif en lugar de la Brioni de la etapa anterior. Según recogía el propio diario, el nuevo diseño busca una mejor diferenciación de los géneros periodísticos, con una estética más arrevistada en los reportajes y una incorporación de destacados más visibles en 
las entrevistas. Asimismo, se han rediseñado los suplementos "Territorios", "Innova", "Jantour" y "GPS". El alzado del diario tras esta modificación queda de la siguiente forma: Portada, Ciudadanos, Actualidad (Política), Opinión, Mundo, Economía, Cultura y Sociedad, Deportes, Vivir, Gente\&TV y Contraportada. En esta organización, siguen siendo plenamente reconocibles los cuatro grandes bloques del rediseño de 2000. Llama la atención la recuperación de la sección "Vivir" en la que se integran temas de salud, bienestar, medio ambiente, nutrición, nuevas tecnologías, etc.; con un planteamiento muy visual y abundancia de infografías.

En la edición de 2018 de los premios NÑ, El Correo recibió el galardón al diario local o regional mejor diseñado.

\subsection{El Periódico de Catalunya}

En su toma de posesión como director de El Periódico de Catalunya -el 3 de junio de 2020- Albert Sáez anunciaba un nuevo rediseño de esta publicación, tanto en su edición en papel como digital2 ${ }^{2}$. Esta publicación inauguró una nueva etapa, en junio de 2019, a raíz de la compra del Grupo Zeta por parte de la cadena Prensa Ibérica, propietaria de 17 cabeceras regionales y locales.

El Periódico de Catalunya nació en Barcelona el 26 de octubre de 1978. Su diseño original fue obra de Fermín Vílchez y Carlos Pérez de Rozas. En 1985, sufrió un rediseño de la mano de Enric Satué y Toni Cases; y una nueva remodelación, en 1990, por parte de Antoni Pelegrín y Xavier Conesa. Prácticamente desde su nacimiento, el diario buscó diferenciarse visualmente. Enrique Arias Vega señalaba que el fundador del grupo Zeta, Antonio Asensio apuntaba la necesidad de un periódico «que sea riguroso en la información pero que al mismo tiempo no haga bostezar a los lectores» (1983: 3).

Entre las señas de identidad de esta publicación, hasta su rediseño de 2000 , figuraba el empleo de un formato berlinés $(32,5 \times 43,5)$, la pauta de seis columnas y la omnipresencia de la Helvética en prácticamente todos los elementos de la publicación.

El Periódico llevó a cabo un espectacular cambio de imagen el 3 de diciembre de 2000, convirtiéndose en el primer diario español en editar la totalidad de sus páginas en color. El rediseño fue obra del estudio Cases i Asociats, que empleó el color como un elemento fundamental de la nueva confección, asignando un determinado color a las diferentes secciones.

El diario redujo su formato y abandonó su pauta de seis columnas pasando a usar una de cinco. También incorporó algunos cambios en la tipografía, al emplear en los textos la Swift en lugar de la Helvética —uno de los ico-

${ }^{2}$ http://www.grupozeta.es/noticias/ 
nos visuales del rotativo-, si bien esta última letra continuaba empleándose en los titulares. Con el nuevo diseño, El Periódico comenzó a venderse grapado y se dividía en dos cuerpos diferenciados. En el primer cuadernillo existían tres bloques. El primero, junto al Tema del Día, acogía las secciones de Internacional, Política y Economía. En el segundo se situaban Cosas de la Vida, Sociedad, Gran Barcelona y Catalunya; y en el tercero, los Deportes. El segundo de los cuerpos estaba formado por una revista diaria denominada Exit y por las secciones de Espectáculos y Agenda.

Imagen 6. Portadas de EI Periódico en 2010 (izquierda) y 2020 (derecha)
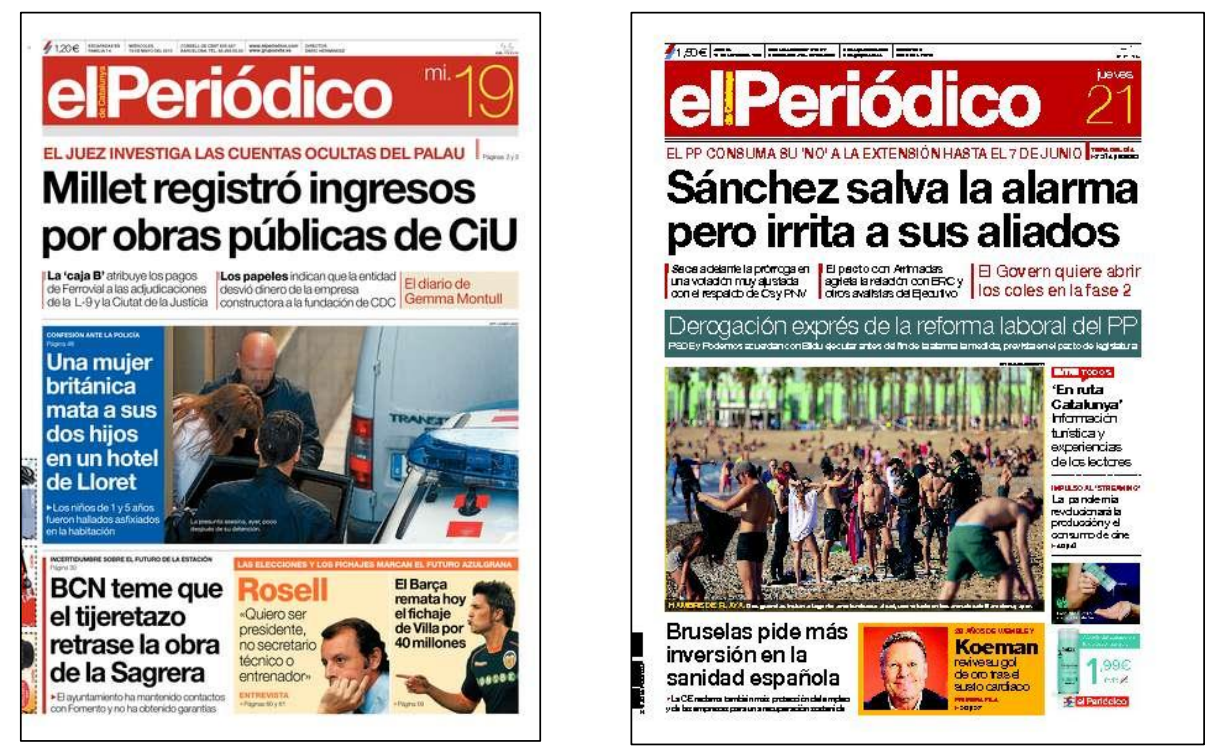

A la espera del anunciado rediseño, El Periódico ha seguido fiel a sus principales señas de identidad visuales durante las dos últimas décadas. Sigue utilizando una portada en la que el espacio esta principalmente ocupado por titulares y fotografías, lo que Evans (1985) denominaba una portada en "póster". La publicación continúa iniciándose con el "Tema del día", con un tono cromático verde. Tras Opinión, viene Internacional, Política y Economía, en las que se utiliza un tono azulado. El segundo bloque, "Cosas de la Vida" (color burdeos, se inicia con Sociedad, seguida de Gran Barcelona y El Tiempo. Por último, el tercer bloque (color anaranjado) agrupa Deportes, Cultura y espectáculos - "iCult" - y televisión. 
El diario mantiene el empleo de formatos de lectura rápida: sumarios, textos de apoyo, despieces de análisis, etc.; y emplea la negrita en algunos de estos textos.

\section{Conclusiones}

Tras el análisis de estas seis publicaciones, podemos establecer algunas conclusiones generales. En primer lugar, los cambios registrados durante la última década en el diseño de la prensa española han tenido, por lo general, un calado menos profundo que los que se produjeron durante finales del siglo XX y primeros años del siglo XXI. De hecho, en la mayoría de los diarios siguen siendo reconocibles algunas de las aportaciones de dicha época como, por ejemplo, los formatos de lectura rápida.

El momento complicado que viven los diarios impresos, con una importante reducción de sus ventas y de sus ingresos publicitarios durante el último decenio, y que se ha visto reflejado en diversos ERE y ajustes de plantillas, posiblemente ha desaconsejado abordar rediseños de gran profundidad. Como explicaban Vizcaíno y Jiménez (2018), el rediseño no parece funcionar en situaciones de crisis manifiesta.

Entre las características formales que parecen consolidadas en 2020, la primera es obvia. El color se ha instalado definitivamente en las páginas de la prensa. Por otro lado, y tal y como ha venido sucediendo en otros países, los tabloides españoles han reducido su tamaño. Cabe recordar que todavía a principios de este siglo no era tan extraño encontrarnos con formatos cercanos al berlinés $(31,5 \times 47 \mathrm{~cm})$. En la actualidad, lo habitual es ver ejemplares con un ancho de $28-30 \mathrm{~cm}$ y una altura de $37-40 \mathrm{~cm}$. Incluso hay cabeceras con tamaño más reducido, como $A b c(26,4 \times 34,7 \mathrm{~cm})$ o La Razón $(29,5 \times 35,4)$. Excepto en $A b c$ (cuatro columnas), la pauta de cinco columnas continúa siendo la habitual, aunque en algunos diarios como El Mundo emplean las seis columnas en varios de sus suplementos (Crónica, DXT, Papel). Se puede hablar de una tendencia al arrevistamiento de los diarios, no sólo por la reducción de sus formatos, sino por la utilización, especialmente en sus suplementos, de determinados recursos visuales que venían siendo característicos de las revistas gráficas (grandes fotografías, color, utilización de gráficos, etc.)

Respecto a la tipografía, las omnipresentes Times y Helvética de finales del siglo XX han pasado a tener una presencia marginal en la prensa de España. Como se detalla en la ya citada investigación de Fernández (2017), en 2016 únicamente ocho de los 96 diarios por él analizados utilizaba alguna de estas dos familias. Entre dichas excepciones figuraba El Periódico de Catalunya y publicaciones del entonces grupo Zeta. Algunos rotativos, como El País o Abc, han recurrido a tipografías de encargo, específicamente diseñadas para estas publi- 
caciones, como la Majerit o la Periódico. Las versiones palo seco continúan siendo una excepción en los textos. En los titulares de la muestra analizada también predominan las romanas (salvo en El Correo y El Periódico), aunque algunas cabeceras utilizan familias sans serif en la sección de Deportes.

Tabla 4. Estilos tipográficos utilizados en la última década

\begin{tabular}{|l|l|l|l|}
\hline & \multicolumn{1}{|c|}{ Titulares } & \multicolumn{1}{c|}{ Textos } & \multicolumn{1}{c|}{ Tit. Opinión } \\
\hline El País & Majerit (Benton en Deportes) & Majerit & Cursiva \\
\hline La Vanguardia & Mercury (Taz en Deportes) & Mercury & Redonda \\
\hline El Mundo & Valencia (Knockout en Deportes) & Imperial & Cursiva \\
\hline Abc & Periódico & Periódico & Redonda \\
\hline El Periódico & Helvética & Swift & Redonda \\
\hline El Correo & Guardian Sans & IBM Plex serif & Redonda \\
\hline
\end{tabular}

Por otro lado, se puede afirmar que la cursiva ha dejado de ser el estilo de letra típica de los titulares de Opinión, algo muy habitual hace unos años por la influencia de El País. De hecho, de la muestra analizada, únicamente El País y El Mundo mantienen este estilo en sus secciones de Opinión.

Como complemento del titular, predomina la utilización de los subtítulos (todas las cabeceras estudiadas los emplean), a menudo en forma de sumario; aunque diarios como El País, La Vanguardia o Abc también recurren a antetítulos en determinados géneros o secciones.

En los textos, casi han desaparecido las entradillas, aunque El País, tras un paréntesis de 8 años, las recuperó a raíz de su rediseño de 2015. Todos los diarios emplean sumarios y la mayoría también ladillos (más excepcionales en el caso de El Mundo y La Vanguardia).

En general, las páginas tienen un aspecto más claro, con menos filetes separadores y más blancos, y son visualmente atractivas. La integración en las redacciones de las versiones impresas y digitales, probablemente se haya reflejado en una mayor influencia de estas segundas en el aspecto formal de las primeras.

El uso de recuadros para destacar los textos más importantes de las páginas, que casi había caído en el olvido, ha sido rescatado en su portada por $L a$ Vanguardia, si bien en un grosor muy fino.

Como reflexión final, cabe preguntarse por el futuro de unos diarios en papel, probablemente mejor diseñados que nunca, pero que asisten impotentes a la huida de lectores y anunciantes hacia el soporte digital. 


\section{Referencias bibliográficas}

AEDE (2003). Libro Blanco de la Prensa. Madrid, España: AEDE.

ÁLVAREZ MARCOS, J. (2017). Las formas de la información: el diseño de los géneros periodísticos en los diarios impresos. En A. Fernández Barredo (coord..), Escribir con estética visual, diseñar con contenido. De cómo la diagramación condiciona los textos periodísticos. Madrid: Fragua, 63-79.

Arias Vega, E. (1983). Cinco años que sólo son el comienzo. En El Periódico de Catalunya 1978-1983. Barcelona: El Periódico, 3-7.

Berelson, B. (1952). Content Analysis in Communications Research. New York: Free Press.

BENITO, M. (2017). ¿Quién dijo que El Mundo es siempre igual? encajabaja.com. Recuperado de https://tinyurl.com/y5vbjk99

CANGA, J. (1995). El diseño periodístico en la prensa diaria. Madrid, España: Síntesis.

CuRTIS, R. (2007). El modelo tipográfico de El Sol. En L. González Díez y P. Pérez Cuadrado (coord.), 30 años de diseño periodístico en España (19762006). Madrid: Zona Impresa, 70-78.

DEL OlMO BARBERO, J. Y PARRAT FERNÁNDEZ, S. (2011). Tipografía y color, un análisis de la prensa gratuita vs. la prensa de pago en España. Revista Latina de Comunicación Social, 66, 376-398.

\section{doi.org/10.4185/RLCS-66-2011-938-376-398}

DíAZ Nosty, B. (2000). Informe anual de la Comunicación 1999-2000. Barcelona, España: Grupo Zeta.

Díaz Nosty, B. (1992). Prensa: Diez años para sobrevivir en Comunicación Social/Tendencias. Informes anuales de Fundesco. Madrid, España: Fundesco.

Diezhandino, P. (1994). Periodismo de servicio. Barcelona, España: Bosch.

Evans, H. (1994). Diseño y compaginación de la prensa diaria. México: Gustavo Gili.

FERNÁNDEZ GONZÁLEZ, H.J. (2017). La paleta tipográfica en la prensa diaria española actual (2016). En VV.AA., Anuario Lletraferits 2017. Reflexiones en torno a la letra. Valencia: Campgrafic, 68-73.

FERNÁNDEZ GONZÁLEZ, H.J. (2016). Las tipografías por encargo en el diseño actual de la prensa española. Comunicación presentada en 7 CIT, Congreso Internacional de Tipografía. Valencia 1-3/07/2016. Recuperado de https://tinyurl.com/yy4pw65v

FRANCO ÁlVAREZ, G. (2004). Un ejemplo de homogeneidad en el diseño periodístico: la identidad gráfica de las portadas del 11-S y del 11-M.Ámbitos, 22, 155-166.

GAITÁN MoYA, J.A. Y PIÑUEL RAIGADA, J.L. (1998). Técnicas de investigación en Comunicación Social. Elaboración y registro de datos. Madrid, España: Síntesis. 
GäDE, R. (2007). Rehinard Gäde: «No hubiera podido crear El País en Alemania». En L. González Díez y P. Pérez Cuadrado (coord.), 30 años de diseño periodístico en España (1976-2006). Madrid: Zona Impresa, 34-39.

GILES, V. y Hodgson, F.W. (2000). Newspaper Design. Oxford, Reino Unido: Heinemann.

GonzÁlez Díez, B., Puebla Martínez, B. y PÉRez Cuadrado, P. (2018). De la maquetación a la narrativa transmedia: una revisión del concepto de 'diseño de la información periodística'. Palabra Clave, 21 (2), 445-468. doi.org/10.5294/pacla.2018.21.2.8

GonzÁlez DíEz, B., Puebla Martínez, B., Birkner, T. y PÉrez Cuadrado, P. (2015). El diseño periodístico como actor fundamental en los modelos de prensa popular. Una aproximación a las causas del cierre del diario Claro. Revista Latina de Comunicación Social, 70, 859-877.

doi.org/10.4185/RLCS-2015-1075

GonzÁlez DíEZ, L. Y PÉREZ CuAdrADo, P. (2007). El Diseño de los Diarios Gratuitos en España. RE-Presentaciones, 2, 141-150.

GonzÁlez DíEz, L. Y PÉREz CuAdrado, P. (2001). Principios Básicos sobre Diseño Periodístico. Madrid, España: Universitas.

HuTT, N. y JAMES, B. (1989). Newspaper Design Today. Londres, Reino Unido: Lund Humhries.

INFOADEX (1996-2020). Resumen Estudio Infoadex de la Inversión Publicitaria en España. Madrid: Infoadex. Recuperado de https://www.infoadex.es

KRIPPENDORFF, K. (1990). Metodología del análisis de contenido. Teoría y práctica. Barcelona, España: Paidós.

LALlAnA, F. (2000). Tipografía y diseño. Madrid, España: Síntesis.

LóPEz Alonso, R. (2013). Diseño de periódicos y revistas en la era digital. Madrid, España: Fragua.

LóPEZ HidAlgo, A. (2017). Las claves del diseño periodístico: fusión de forma y contenido. En A. Fernández Barredo (coord.), Escribir con estética visual, diseñar con contenido. De cómo la diagramación condiciona los textos periodísticos. Madrid, España: Fragua, 19-32.

MARTínEZ-FRESNEDA OSORIO, H. (2008). El diseño periodístico, clave en la lectura crítica de la prensa. Comunicar, 25(30), 179-184.

MejÍA CHIANG, C. (2017). Arrevistamiento en el diseño de primeras planas de un diario generalista español. Las portadas del diario Público. Correspondencias \& Análisis, 7, 137-156.

doi.org/10.24265/cian.2017.n7.08

MoEN, D.R. (1989). Newspaper Layout and Design. Ames, Estados Unidos de América: Iowa State University Press. 
Puebla Martínez, B.; GonzÁlez DíEz, L. y PÉRez CuAdrado, P. (2015). Las cabeceras de la prensa diaria como refuerzo de la identidad de marca en los periódicos deportivos españoles impresos y online. Fonseca. Journal of Communicationi, 10, 50-78.

REHE, R. (2000). Tipografía y diseño de periódicos. Ames, Estados Unidos de América: Iowa State University Press.

SABÉS TuRMo, F. (2008). El rediseño de La Vanguardia y la aparición de Público: dos formatos informativos coetáneos. Trípodos, 22, 119-136.

SuÁrez CARballo, F.; MARTín SAn Román, J.R., y Nó SÁnCHEZ, J. (2014). La hiperfragmentación informativa en el Diseño Periodístico Impreso: propuesta metodológica y análisis de repercusiones cognitivas. Icono 14, 12(1), 63-104. doi.org/10.7195/ri14.v12i1.627

SuÁrez CARBAllo, F. (2008). Fundamentos del diseño periodístico: claves para interpretar el lenguaje visual del diario. Pamplona, España: Eunsa.

SubiEla HERnÁNDEZ, B.J. y Gómez-Company, A. (2018). Influencia del diseño periodístico en la comprensión de la información. El Profesional de la Información, 27(1), 115-124. doi.org/10.3145/epi.2018.ene.11

SUBIELA HERNÁNDEZ, B.J. (2018). La retórica de la imagen en el diseño periodístico: del modelo publicitario al informativo. Arquetipo, 17, 9-24.

SUBIELA HERNÁNDEZ, B.J. y GoBANTES BILBAO, M. (2010). La retórica visual en el diseño periodístico: Un diagnóstico. En P. Pérez Cuadrado y B. Puebla Martínez (coord.), II Jornadas de Diseño en la Sociedad de la Información. Aplicaciones, experiencias y prospectivas de la fotografía. Madrid: Universidad Rey Juan Carlos, 31-39.

Torregrosa, A. (2007). El diario de servicios. Alberto Torregrosa: La identidad del diario frente a la uniformidad. En L. González Díez y P. Pérez Cuadrado (coord.), 30 años de diseño periodístico en España (1976-2006). Madrid, España: Zona Impresa, 162-171.

VílCHEZ DE ARRIBAS, J.F. (2007). El País, el triunfo de la sencillez. En L. González Díez y P. Pérez Cuadrado (coord.), 30 años de diseño periodístico en España (1976-2006). Madrid, España: Zona Impresa, 22-32.

VÍLCHEZ DE ARRIBAS, J.F. (2011). Historia gráfica de la prensa diaria española (1758-1976). Barcelona, España: RBA.

Vilmos, N. y AlADÁR, R. (1986). Diseño de periódicos. Quito, Ecuador: Ciespal.

VIZCAÍNO-LAORGA, R. y JimÉnEZ-RUESTA, J. (2018). Rediseño en la prensa impresa española del siglo XXI. El Profesional de la Información, 27(1), 124-136. doi.org/10.3145/epi.2018.ene.12

ZoRrilla, J. (1997). Introducción al diseño periodístico. Pamplona, España: Eunsa. 